\title{
Epidemiology and treatment of phalangeal fractures: conservative treatment is the predominant therapeutic concept
}

\author{
Laura Kremer $^{1} \cdot$ Johannes Frank $^{1} \cdot$ Thomas Lustenberger $^{1} \cdot$ Ingo Marzi $^{1} \cdot$ Anna Lena Sander $^{1,2}$ (D)
}

Received: 12 March 2020 / Accepted: 11 May 2020 / Published online: 25 May 2020

(c) The Author(s) 2020

\begin{abstract}
Purpose Despite the high number of patients with phalangeal fractures, evidence-based recommendations for the treatment of specific phalangeal fractures could not be concluded from the literature. The purpose of the present study was to assess current epidemiological data, classification of the fracture type, and mode of treatment.

Methods This study presents a retrospective review of 261 patients with 283 phalangeal fractures $\geq 18$ years of age who were treated in our level I trauma centre between 2017 and 2018. The data were obtained by the analysis of the institution's database, and radiological examinations.

Results The average age of the patients was 40.4 years (range 18-98). The ratio of male to female patients was 2.7:1. The two most typical injury mechanisms were crush injuries (33\%) and falls (23\%). Most phalangeal fractures occurred in the distal phalanx (P3 43\%). The 4th ray (D4 29\%) was most frequently affected. The P3 tuft fractures, and the middle phalanx (P2) base fractures each accounted for $25 \%$ of fracture types. A total of $74 \%$ of fractures were treated conservatively, and $26 \%$ required surgery, with Kirschner wire(s) (37\%) as the preferred surgical treatment. The decision for surgical treatment correlated with the degree of angular and/or rotational deformity, intraarticular step, and sub-/luxation of specific phalangeal fractures, but not with age and gender.

Conclusions Our findings demonstrated the popularity of conservative treatment of phalangeal fractures, while surgery was only required in properly selected cases. The correct definition of precise fracture pattern in addition to topography is essential to facilitate treatment decision-making.
\end{abstract}

Keywords Phalangeal fractures $\cdot$ Epidemiology $\cdot$ Fracture type $\cdot$ Classification $\cdot$ Treatment

\section{Introduction}

Phalangeal fractures are common injuries and can be complicated by deformity without sufficient treatment and stiffness due to inadequate immobilisation or overtreatment [1-3]. Despite the high number of patients, evidence-based recommendations for the treatment of specific phalangeal fractures could not be concluded from the literature and randomised controlled trials are prevented from being performed due to the wide range of variation in fracture patterns

Anna Lena Sander

AnnaLena.Sander@kgu.de

1 Department of Trauma, Hand and Reconstructive Surgery, University Hospital Frankfurt, Frankfurt am Main, Germany

2 Klinik für Unfall-, Hand- und Wiederherstellungschirurgie, Universitätsklinikum Frankfurt, Theodor-Stern-Kai 7, 60590 Frankfurt am Main, Germany and the associated variables that are thought to affect treatment and outcome [4]. In this context, it is also evident that there is a lack of a comprehensive and generally accepted classification [5-8]. This study was performed to evaluate current epidemiological data, classification of the fracture type, and mode of treatment.

\section{Patients and methods}

Institutional review board approval (GN239/16) was obtained prior to initiating this retrospective study. The study included all patients $\geq 18$ years of age with phalangeal fractures who were treated in our level I trauma centre over a 2-year period (2017-2018). An electronic ICD-10 search was conducted and 261 patients were identified. The data were collected by the analysis of the institution's database, and radiological examinations. Information 
obtained included age, gender, injury mechanism, injured side, phalanx, ray, fracture type, and mode of treatment. Injury mechanism was divided into the following categories: crush injury, jam injury (axial loading to the tip of the finger), distorsion, hyperextension, fall from standing or seating height, violent assault, bicycle accident, motor vehicle accident, and other/unclear. All patients underwent standard of care imaging that included radiographs in two planes. Computed tomography (CT) imaging was used in $6 \%(17 / 283)$ of fractures, of which 53\% (9/17) were intraarticular, and 47\% (8/17) extraarticular. The phalangeal fractures were classified according to the topography using preoperative radiological imaging (Table 1) [3, 9]. Stable and reducible fractures, which do not displace in a cast in the first 5-14 days after reduction, were treated nonoperatively. The indication for surgical fixation included angular and/or rotational deformity, intraarticular impression and/or step $>2 \mathrm{~mm}$, and sub-/luxation. All operative patients were treated by surgeons specialised in orthopaedic trauma care. Statistical evaluation was performed using Chi-square test. Values of $p<0.05$ were considered statistically significant.

\section{Results}

The average age was 40.4 years (range 18-98) consisting of $90 \%(235 / 261)$ adult patients ( $<65$ years), and 10\% (26/261) elderly patients ( $\geq 65$ years). The ratio of male to female patients was $2.7: 1$. The average age of males was 39 years

Table 1 Topographical classification of phalangeal fractures

P3
Tuft fracture
Shaft fracture
Base fracture
Volar avulsion (profundus avulsion)
Dorsal avulsion (mallet fracture)
Lateral avulsion
Base fracture
P1/P2
Condylar fracture
Unicondylar fracture
Bicondylar fracture
Neck fracture
Shaft fracture
Base fracture
P2 volar avulsion
P2 dorsal avulsion
P1/P2 lateral avulsion
P2 pilon fracture
P1 base fracture

(range 18-83) with 94\% (178/190) adult patients, and 6\% (12/190) elderly patients, and 44.1 years (range 18-98) for females with 80\% (57/71) adult patients, and 20\% (14/71) elderly patients. In the elderly population, significantly more female compared to male patients were found $(p=0.001)$. The most typical injury mechanism was crush injury (33\%, $87 / 261)$ followed by accidental fall $(23 \%, 61 / 261)$, and jam injury $(15 \%, 40 / 261) .29 \%$ (76/261) of the accidents occurred at work. The ratio of right $(53 \%, 138 / 261)$ to left $(47 \%, 123 / 261)$ hands was $1.1: 1$. The 261 patients had 283 fractures, including $7 \%$ (18/261) of patients with multiple fractures. Of these, $83 \%(15 / 18)$ had two fractures, $11 \%$ $(2 / 18)$ three fractures, and 6\% (1/18) four fractures, with the multiple fractures most commonly $(72 \%, 13 / 18)$ at the same level [e.g., adjacent distal phalanx (P3)] (Table 2).

$43 \%(121 / 283)$ of the phalangeal fractures occurred in the $\mathrm{P} 3,30 \%(85 / 283)$ in the middle phalanx (P2), and $27 \%$ (77/283) in the proximal phalanx (P1). The 4th ray (D4 29\%, $82 / 283$ ) was most frequently affected followed by the 5 th (D5 25\%, 71/283), and the 3rd (D3 19\%, 53/283). Evaluating the distribution of phalanx versus ray, the $\mathrm{P} 3$ of the $\mathrm{D} 4$ $(12 \%, 35 / 283)$ was most commonly injured followed by the P2 of the D4 (12\%, 33/283), and the P3 of the D3 (11\%, 30/283) (Fig. 1).

Analysing the distribution of phalanx versus fracture type, P3 tuft fractures $(25 \%, 72 / 283)$, and P2 base fractures $(25 \%, 70 / 283)$ were the most common fracture types followed by P1 base fractures (17\%, 48/283) (Table 3).

Table 2 Epidemiological and injury details

\begin{tabular}{ll}
\hline Number of patients & 261 \\
Age (years) & $40.4(18-98)$ \\
Gender (male:female) & $2.7: 1$ \\
Injury mechanism & \\
Crush injury & $33 \%(87 / 261)$ \\
Fall from standing or seating height & $23 \%(61 / 261)$ \\
Jam injury & $15 \%(40 / 261)$ \\
Violent assault & $6 \%(16 / 261)$ \\
Bicycle accident & $6 \%(15 / 261)$ \\
Hyperextension & $5 \%(14 / 261)$ \\
Other/unclear & $5 \%(12 / 261)$ \\
Distorsion & $4 \%(10 / 261)$ \\
Motor vehicle accident & $2 \%(6 / 261)$ \\
Injured side & \\
Right & $53 \%(138 / 261)$ \\
Left & $47 \%(123 / 261)$ \\
Number of fractures & 283 \\
Patients with multiple fractures & $7 \%(18 / 261)$ \\
2 & $83 \%(15 / 18)$ \\
3 & $11 \%(2 / 18)$ \\
4 & $6 \%(1 / 18)$ \\
\hline
\end{tabular}




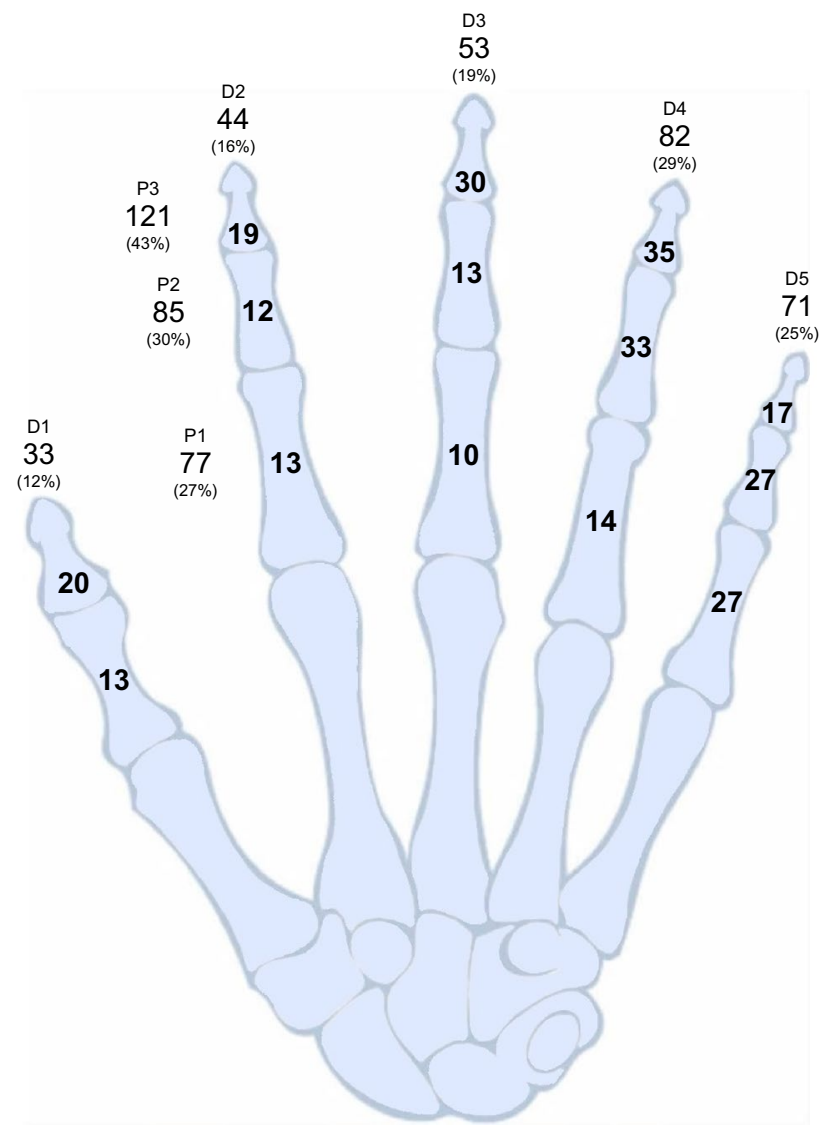

Fig. 1 The distribution of phalangeal fractures by phalanx and ray

Table 3 Distribution of phalanx versus fracture type

\begin{tabular}{ll}
\hline P3 & \\
Tuft fracture & $25 \%(72 / 283)$ \\
Shaft fracture & $4 \%(10 / 283)$ \\
Base fracture & $14 \%(39 / 283)$ \\
P2 & \\
Condylar fracture & $1 \%(2 / 283)$ \\
Neck fracture & $1 \%(3 / 283)$ \\
Shaft fracture & $4 \%(10 / 283)$ \\
Base fracture & $25 \%(70 / 283)$ \\
P1 & \\
Condylar fracture & $1 \%(4 / 283)$ \\
Neck fracture & $0.4 \%(1 / 283)$ \\
Shaft fracture & $8 \%(24 / 283)$ \\
Base fracture & $17 \%(48 / 283)$ \\
\hline
\end{tabular}

Subdividing the base, the most typical fracture type of the P1 was the base fracture $(65 \%, 31 / 48)$ compared to volar avulsion $(80 \%, 56 / 70)$ in the $\mathrm{P} 2$, and base fracture $(44 \%$, 17/39) in the P3 (Table 4).
Table 4 Distribution of base versus fracture type

\begin{tabular}{ll}
\hline P3 base & \\
\hline Base fracture & $44 \%(17 / 39)$ \\
Dorsal avulsion & $31 \%(12 / 39)$ \\
Volar avulsion & $21 \%(8 / 39)$ \\
Lateral avulsion & $5 \%(2 / 39)$ \\
P2 base & \\
Volar avulsion & $80 \%(56 / 70)$ \\
Pilon fracture & $9 \%(6 / 70)$ \\
Lateral avulsion & $9 \%(6 / 70)$ \\
Dorsal avulsion & $3 \%(2 / 70)$ \\
P1 base & \\
Base fracture & $65 \%(31 / 48)$ \\
Lateral avulsion & $33 \%(16 / 48)$ \\
Volar avulsion & $2 \%(1 / 48)$ \\
\hline
\end{tabular}

Table 5 Distribution of phalanx versus mode of treatment

\begin{tabular}{lll}
\hline & Operative & Nonoperative \\
\hline P3 & $29 \%(35 / 121)$ & $71 \%(86 / 121)$ \\
P2 & $13 \%(11 / 85)$ & $87 \%(74 / 85)$ \\
P1 & $35 \%(27 / 77)$ & $65 \%(50 / 77)$ \\
\hline
\end{tabular}

$41 \%(115 / 283)$ of fractures were intraarticular, and 59\% $(168 / 283)$ extraarticular, with $4 \%(12 / 283)$ of fractures resulting in joint luxation. Of these, $75 \%$ (9/12) of fractures occurred in the $\mathrm{P} 2$, and $25 \%(3 / 12)$ in the $\mathrm{P} 3$, with volar avulsion $(92 \%, 11 / 12)$ as most typical fracture type. Closed fractures accounted for 87\% (247/283) of fractures compared to $13 \%(36 / 283)$ open fractures with significant soft tissue injuries communicating with the fractures.

$74 \%(210 / 283)$ of the fractures could be treated conservatively, respectively $26 \%$ (73/283) with surgery. Reviewing the relationship between age and mode of treatment, $75 \%$ (188/251) of the adult patients were managed without surgery, and 25\% (63/251) with surgery compared to $69 \%(22 / 32)$, and $31 \%(10 / 32)$ of the elderly patients. Evaluating the distribution of gender versus mode of treatment, males were treated conservatively in 74\% (150/204), and with surgery in 26\% (54/204) versus $76 \%$ (60/79), and $24 \%$ (19/79) for females. The differences were not statistically significant. Therefore, in the present study population, the decision for surgical treatment was independent of age $(p=0.454)$ and gender $(p=0.676)$.

Analysing the distribution of phalanx versus mode of treatment, $65 \%(50 / 77)$ of $\mathrm{P} 1$ fractures could be treated conservatively, and $35 \%$ (27/77) with surgery compared to P2 fractures with $87 \%(74 / 85)$ versus $13 \%(11 / 85)$, 
and P3 fractures with 71\% (86/121) versus 29\% (35/121) (Table 5).

Kirschner wire(s) $(37 \%, 27 / 73)$ predominated the surgical treatment followed by sutures of the nail bed $(22 \%, 16 / 73)$ and locking plates $(16 \%, 12 / 73)$ (Table 6$)$.

\section{Discussion}

Age and gender are both important factors for defining the risk of sustaining phalangeal fractures [10]. Young males and elderly females are known to be most susceptible for this injury $[2,10,11]$. Males remain at a relatively greater risk for phalangeal fractures than females up until the age of 60 likely resulting from increased behavioural risk factors such as participation in higher risk sport and occupational activities until the age of retirement $[10,12]$. Females begin to show a greater risk after the age of 65 due to a longer life expectancy with exponential increase in the incidence of falls and osteoporosis $[13,14]$. The age and gender distribution of the present study was congruent with those published demonstrating predominantly adult male patients and a larger female proportion in the elderly population.

The two most typical injury mechanisms are direct blow and accidental fall, with a variable distribution in the different age groups $[4,15]$. De Jonge et al. showed that falls are responsible for most of phalangeal fractures in patients over 70 years, in contrast to another study, in which the majority of the fractures were caused by a direct, or crush injury, even in the retired population $[1,15]$. Our data demonstrated that adult patients sustained predominantly crush injury whereas falls occurring primarily in elderly patients consistent with the study of de Jonge et al. [1].

The ratio of right and left hands of phalangeal fractures has been reported to be 1:1 in previous studies which is similar to the present study population $[14,16]$. Hence, right-hand dominance does not result in higher incidence of phalangeal fractures of the right hand $[14,17]$.

The D5, as border ray, has been shown to be most frequently affected $[4,15]$. However, we noticed that our ray profile differed, in which the D4 was most commonly injured confirming the theory that the incidence

Table 6 Mode of surgical treatment

\begin{tabular}{ll}
\hline Kirschner wire(s) & $37 \%(27 / 73)$ \\
Suture of the nail bed & $22 \%(16 / 73)$ \\
Locking plate & $16 \%(12 / 73)$ \\
Suture anchor & $8 \%(6 / 73)$ \\
Dynamic distraction external fixator & $8 \%(6 / 73)$ \\
Screw(s) & $7 \%(5 / 73)$ \\
Mini external fixator & $1 \%(1 / 73)$ \\
\hline
\end{tabular}

of phalangeal fractures is proportional to the length of the digit [18]. Congruently, most phalangeal fractures occurred in the $\mathrm{P} 3$ reflecting the kind of injury mechanism (crush injury) in our study population.

Few data are available in the literature regarding fracture type of phalangeal fractures [15]. Stanton et al. found that the P3 tuft and base were common sites of injury, in which intraarticular fractures were rare [15]. Our study revealed a different distribution of fracture types which were also classified according to the topography (Table 1) $[3,9]$. The two most frequent fracture types were P3 tuft and $\mathrm{P} 2$ base fractures. The most vulnerable parts of the P1 and $\mathrm{P} 2$ were their bases accounting for $73 \%$ of fractures. Subdividing the base, the most common fracture type of the P1 was the base fracture compared to volar avulsion in the P2. Intraarticular fractures represented a large proportion of all fractures, which could be explained, in part, by the different injury mechanism.

The majority of phalangeal fractures can be treated without an operation $[2,15,19]$. Our data were consistent with the conservative trend, but the percentage of fractures treated surgically was higher compared to the current literature. This could be due to the higher number of intraarticular fractures in our trauma centre, which accounted for $34 \%$ of fractures requiring surgery.

Age has been shown to be the most important variable in determining whether operative or nonoperative management is appropriate, with advanced age more predictive of nonoperative management [20]. Contrarily, in the present study, elderly patients were just as likely to get surgical treatment as adult patients due to a variety of reasons. First, the high percentage of intraarticular fractures (34\%). Second, it was also due to a personal request of the elderly patients who are now more active than ever and often prefer surgical treatments that do not hamper their activities.

Kirschner wires and screw-plate fixation generally predominate in the various modes of surgical treatment [4, 15, 21]. Similarly, in our study, Kirschner wire(s) were required in most cases, while the proportion of locking plates was lower. The further fixation methods included suture anchor, dynamic distraction external fixator, screw(s), and mini external fixator in that order reflecting the kind of fracture pattern with a high number of intraarticular fractures in our study population.

Some limitations must be considered for the present study. First, the study design was retrospective. Second, our data provided no information on outcomes. Even though this study contributes to currently available epidemiological data, the definite answer regarding appropriate algorithm for phalangeal fractures requires prospective long-term outcome studies. 


\section{Conclusion}

In conclusion, our results validated the trend of conservative treatment for the vast majority of phalangeal fractures. Surgery, however, was required in properly selected cases depending on the degree of angular and/or rotational deformity, intraarticular impression and/or step, and sub-/ luxation, with the use of Kirschner wire(s) as preferred surgical treatment. The correct definition of precise fracture pattern in addition to topography is essential to facilitate clinical treatment decision-making.

Acknowledgements Open Access funding provided by Projekt DEAL.

\section{Compliance with ethical standards}

Conflict of interest L. Kremer, J. Frank, T. Lustenberger, I. Marzi, and A. L. Sander declare that they have no conflict of interest.

Ethical approval All procedures performed in the study involving human participants were in accordance with the ethical standards of the institutional research committee and with the 1964 Helsinki Declaration and its later amendments or comparable ethical standards.

Informed consent Informed consent was obtained from all individual participants included in the study.

Open Access This article is licensed under a Creative Commons Attribution 4.0 International License, which permits use, sharing, adaptation, distribution and reproduction in any medium or format, as long as you give appropriate credit to the original author(s) and the source, provide a link to the Creative Commons licence, and indicate if changes were made. The images or other third party material in this article are included in the article's Creative Commons licence, unless indicated otherwise in a credit line to the material. If material is not included in the article's Creative Commons licence and your intended use is not permitted by statutory regulation or exceeds the permitted use, you will need to obtain permission directly from the copyright holder. To view a copy of this licence, visit http://creativecommons.org/licenses/by/4.0/.

\section{References}

1. De Jonge JJ, Kingma J, van der Lei B, Klasen HJ. Phalangeal fractures of the hand. An analysis of gender and age-related incidence and aetiology. J Hand Surg Br. 1994;19:168-70.
2. Meals C, Meals R. Hand fractures: a review of current treatment strategies. J Hand Surg Am. 2013;38:1021-31.

3. Sander AL, Marzi I, Frank J. Operative and nonoperative treatment of phalangeal fractures. Chir Prax. 2018;83:611-9.

4. Henry MH. Fractures of the proximal phalanx and metacarpals in the hand: preferred methods of stabilization. J Am Acad Orthop Surg. 2008;16:586-95.

5. Frangen TM, Muhr G, Kälicke T. Phalangeal fractures. Trauma Berufskrankh. 2007;9:212-5.

6. Petracić B, Siebert H. AO-classification of fractures of the hand bones. Handchir Mikrochir Plast Chir. 1998;30:40-4.

7. Schaefer M, Siebert HR. Finger and metacarpal fractures. Surgical and nonsurgical treatment procedures. I. Unfallchirurg. 2000;103:482-94.

8. Windolf J, Siebert H, Werber KD, Schädel-Höpfner M. Treatment of phalangeal fractures: recommendations of the hand surgery group of the German trauma society. Unfallchirurg. 2008;111:331-8.

9. Green DP, Hotchkiss RN, Pederson WC. Green's operative hand surgery. 4th ed. New York: Churchill Livingstone; 1999.

10. Feehan LM, Sheps SB. Incidence and demographics of hand fractures in British Columbia, Canada: a population-based study. J Hand Surg Am. 2006;31:1068-74.

11. Chung KC, Spilson SV. The frequency and epidemiology of hand and forearm fractures in the United States. J Hand Surg Am. 2001;26:908-15.

12. Larsen CF, Mulder S, Johansen AM, Stam C. The epidemiology of hand injuries in The Netherlands and Denmark. Eur J Epidemiol. 2004;19:323-7.

13. Lips P. Epidemiology and predictors of fractures associated with osteoporosis. Am J Med. 1997;103:3-8.

14. van Onselen EB, Karim RB, Hage JJ, Ritt MJ. Prevalence and distribution of hand fractures. J Hand Surg Br. 2003;28:491-5.

15. Stanton JS, Dias JJ, Burke FD. Fractures of the tubular bones of the hand. J Hand Surg Eur. 2007;32:626-36.

16. Barton N. Fractures of the phalanges of the hand. Hand 1977;9:1-10.

17. Llaurens V, Raymond M, Faurie C. Why are some people lefthanded? An evolutionary perspective. Philos Trans R Soc Lond B Biol Sci. 2009;364:881-94.

18. Brown PW. A review of digital injuries. Br J Plast Surg. 1967;20:387-91.

19. Barton NJ. Fractures of the hand. J Bone Joint Surg Br. 1984;66:159-67.

20. Court-Brown CM, Aitken S, Hamilton TW, Rennie L, Caesar B. Nonoperative fracture treatment in the modern era. J Trauma. 2010;69:699-707.

21. Ip WY, Ng KH, Chow SP. A prospective study of 924 digital fractures of the hand. Injury. 1996;27:279-85. 